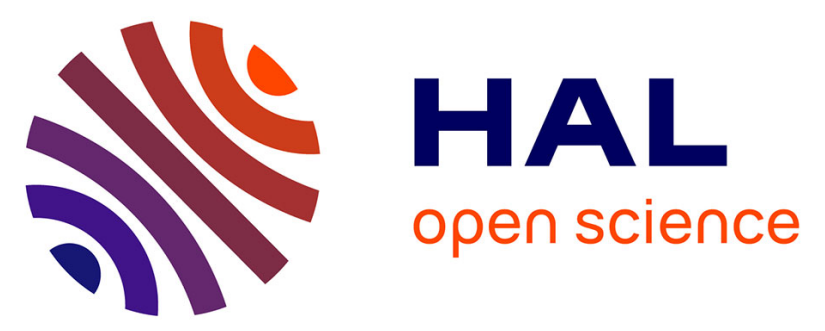

\title{
Wettability Contrasts in Kaolinite and Illite Clays : Characterization by Infrared and X-ray Absorption Spectroscopies
}

\author{
J.-L. Bantignies, C. Cartier Dit Moulin, H. Dexpert
}

\section{To cite this version:}

J.-L. Bantignies, C. Cartier Dit Moulin, H. Dexpert. Wettability Contrasts in Kaolinite and Illite Clays: Characterization by Infrared and X-ray Absorption Spectroscopies. Journal de Physique IV Proceedings, 1997, 7 (C2), pp.C2-867-C2-869. 10.1051/jp4:1997261 . jpa-00255344

HAL Id: jpa-00255344

https://hal.science/jpa-00255344

Submitted on 1 Jan 1997

HAL is a multi-disciplinary open access archive for the deposit and dissemination of scientific research documents, whether they are published or not. The documents may come from teaching and research institutions in France or abroad, or from public or private research centers.
L'archive ouverte pluridisciplinaire HAL, est destinée au dépôt et à la diffusion de documents scientifiques de niveau recherche, publiés ou non, émanant des établissements d'enseignement et de recherche français ou étrangers, des laboratoires publics ou privés. 


\title{
Wettability Contrasts in Kaolinite and Illite Clays: Characterization by Infrared and X-ray Absorption Spectroscopies
}

\author{
J.-L. Bantignies, C. Cartier Dit Moulin and H. Dexpert \\ Laboratoire pour l'Utilisation du Rayonnement Électromagnétique, bâtiment 209D, \\ Université Paris-Sud, 91405 Orsay, France
}

\begin{abstract}
A reservoir rock is a porous geological formation in contact with two liquids : brine and oil. An improved knowledge of rock wettability is of primary importance to estimate the amount of crude oil in underground resources. The petroleum industries have observed that wettability contrasts in sedimentary reservoir rocks are largely correlated to the presence of clays (illite and/or kaolinite) in the rock's intergranular space. More precisely, the grain surfaces of illite show a preference to brine. Kaolinite preferentially adsorbs oil, which imparts its hydrophobic characteristics to the mineral surface. Using X-ray absorption and Fourier Transform Infrared spectroscopies, we studied at the atomic level the adsorption process of asphaltenes in the presence of water. We show experimentally that the wettability contrasts observed in kiolinite and illite are related to structural differences between these two clays and we show the primordial role of the grain surface hydroxyls. At last, the role of the water in the asphaltenes adsorption process has been investigated, using the same spectroscopies.
\end{abstract}

\section{INTRODUCTION}

The petroleum crisis led to a significant research effort in the development of new methods for oil recovery from fields. On the average, 5 to $25 \%$ of the total oil in place in an underground reservoir can be recovered by natural depletion; whereas 10 to 20 \% more oil may be extracted by waterflooding or gas injection. The remaining fraction, target of the new methods, is mainly associated with petroleum components adsorbed on rocks. In this context, the understanding of the rock wettability mechanism is of primary importance to estimate the amount of crude oil in underground resources [1].

The distribution of fluids in the porous medium obtained by Scanning Electron Microscopy at cryogenic temperatures (cryo-SEM) clearly shows that, in the intergranular space, oil is associated with kaolinite. The grain surfaces of illite show a preference for brine. Numerous studies were performed at the macroscopic level in order to characterize the thermodynamics parameters of the clay surface related to the adsorption process. An improved understanding of the process of oil wettability on clays at the microscopic level is required to characterize more precisely the physical or chemical interactions between oil and clay.

An X-ray Absorption Spectroscopy (XAS) investigation was undertaken to follow the adsorption process at the local scale. Since the aluminum and silicon sites in clays are able to contract chemical interactions with the asphaltenes of the oil, the local environment around $\mathrm{Al}$ and $\mathrm{Si}$ atoms in kaolinite have been investigated by Extended X-Ray Absorption Fine Structure (EXAFS) and X-Ray Absorption Near Edge Structure (XANES). The sample (Kaolinite de Ploemeur, hydrothermal, neoformed) have been studied before and after contact with asphaltenes (Safaniya, Saudi Arabia), with and without water. To our knowledge this work is the first XAS characterization of clays samples wetted by organic compounds.

Hydroxyl groups are largely present at the surface of the kaolinite layers where the octahedral sheet, which forms 1 of the 2 basal planes (TO structure), consists of hydroxyl groups bonded to Al. Complementary investigation by Fourier Transform Infra-Red spectroscopy (FTIR) of the hydroxyl group vibration region ( 3550 to $3750 \mathrm{~cm}^{-1}$ ) was carried out in order to study the structural modifications induced by the adsorption process.

\section{ADSORPTION IN PRESENCE OF WATER : RESULTS}

The natural materials were first purified and exchanged with $\mathrm{Na}^{+}$by the addition of the appropriate chloride salt and grains smaller than $2 \mu \mathrm{m}$ in diameter were then recovered by sedimentation. The mean structural composition formulas, the origins of the samples and the preparation method have been described previously [2].

The wetting procedure has been described previously [3] so that $2.4 \mathrm{mg} / \mathrm{m}^{2}$ of asphaltenes were adsorbed on the surface of kaolinite and $1.4 \mathrm{mg} / \mathrm{m}^{2}$ on the surface of the illite. The contact has been made in presence of water (solution of toluene saturated by water) to mimic the competition of the two fluids at the surface of the clays.

\subsection{FTIR spectroscopy}

The spectra were recorded in transmission mode with a $1 \mathrm{~cm}^{-1}$ resolution. $\mathrm{KBr}$ pellets were made to obtain an isotropic distribution of the grains in the samples. A mixture of $1.5 \mathrm{mg}$ of clay and $300 \mathrm{mg}$ of $\mathrm{KBr}$ was gently stirred for about 2 
minutes without exerting any pressure that could induce preferential orientations of the grains. The reproducibility of the results was checked with 20 samples for each compound.

Transmission IR spectra of the $\mathrm{O}-\mathrm{H}$ stretching region are presented in figure 1 .

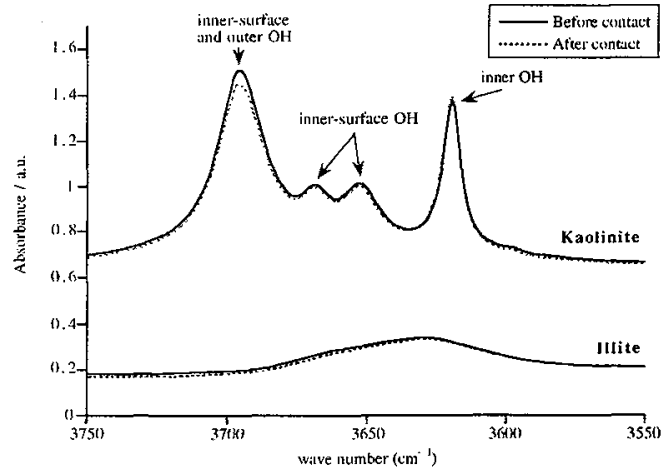

Figure 1 : FTIR transmission spectra of kaolinite and illite before and after contact with asphaltenes in presence of water.

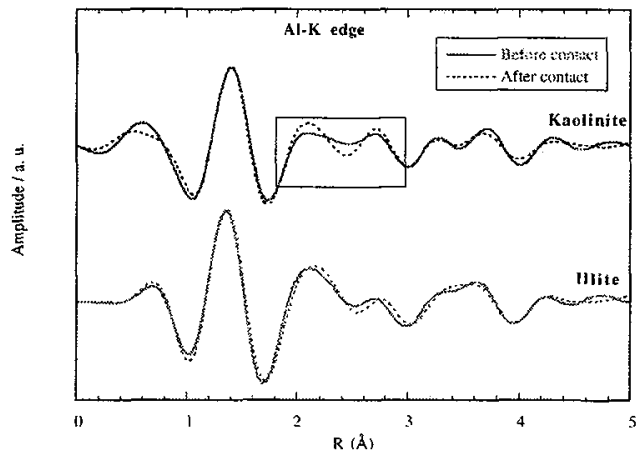

Figure 2 : imaginary parts of the Fourier transtorms of $k$-weight EXAFS spectra for kaolinite and illite before and after contact with asphaltenes.

For the kaolinite, the band at $3622 \mathrm{~cm}^{-1}$ is assigned to the inner $\mathrm{OH}$ stretching vibrational mode located in the volume of the layer. The bands at 3655 and $3670 \mathrm{~cm}^{-1}$ are assigned to the inner-surface OH groups located on the surface of the octahedral sheet sandwiched between two layers. The band at $3700 \mathrm{~cm}^{-1}$ reflects several OH stretching contributions : the inner surface $\mathrm{OH}$ groups and the "outer hydroxyls" which refer to the $\mathrm{OH}$ groups at the surface of the micro crystals, including hydroxyl groups at the broken edges [4].

The adsorption process does not affect the inner-surface $\mathrm{OH}$ bands at $3655 \mathrm{~cm}^{-1}$ and $3670 \mathrm{~cm}^{-1}$. In contrast, the outer-surface $\mathrm{OH}$ band at $3700 \mathrm{~cm}^{-1}$ is affected. We observe a small, but significant decrease of the intensity, and no shift of the maximum position. Two kinds of $\mathrm{OH}$ groups contribute to this peak : those which give vibrations from interlayer hydroxyls and those vibrating at the surface of the grains. Knowing that contact with asphaltenes does not modify the stacking of the layer, it is therefore thought that only hydroxyls groups belonging to the surface are affected by the phenomenon. Thus, the evolution of the band at $3700 \mathrm{~cm}^{-1}$ can be attributed to modifications occurring to the OH located at the surface of the grain, due to the presence of adsorbed asphaltenes.

For the illite, the asphaltenes adsorption does not affect the $\mathrm{OH}$ stretching broad band. Due to the TOT structure of this material, the number of surface $\mathrm{OH}$ groups is much lower than for kaolinite because only the OH at the grains broken edges can be considered. The major part of the signal is thus coming from the $\mathrm{OH}$ intrasheet vibrators, which are not affected by the adsorption process.

We have shown that, for kaolinite, the adsorption of asphaltenes induces a modification of the $\mathrm{OH}$ vibrations. The small amplitude of the variations confirms that the interactions between asphaltenes and clays are weak, probably Van der Waals forces. For the illite sample, no evolution of the $\mathrm{OH}$ stretching region with the asphaltenes adsorption can be observed. To go further with these IR results, we performed an XAS study to characterize the AI and Si environments and to follow their evolutions after contact with the asphaltenes.

\subsection{X-ray absorption spectroscopy}

$\mathrm{Al}$ and $\mathrm{Si}-\mathrm{K}$ edge XAS experiments were carried out on the SA32 beam line installed at the Super-ACO storage ring of LURE (Orsay, France). Data were collected in the total electron yield mode. This detection mode increases the sensitivity to the surface of the samples, compared to the transmission mode detection which is of course bulk sensitive.

The imaginary parts of the pseudo-radial distributions of the $\mathrm{Al}$ neighborhood are reported on figure 2.

For the kaolinite, above the first shell (up to $2 \AA$ ), the imaginary part of the Fourier transform shows a weak but significant modification. This means that at longer distances $(>2 \AA)$, the neighborhood of the aluminum atoms is modified by the asphaltenes adsorption, a significant number of $\mathrm{Al}$ atoms giving a different signal in the EXAFS spectrum. This evolution is in agreement with those observed in the XANES part of the spectra and lead to the same conclusion $[5,6]:$ the contact affects the neighborhood of the $\mathrm{Al}$ atoms of the kaolinite.

For the illite, the imaginary part of the Fourier transforms are superimposable before and after contact, up to $4 \AA$, indicating that no variation of the atomic arrangement around the Al atoms, due to the adsorption process, is detected. This result is also in agreement with our previous XANES investigations.

\section{ADSORPTION IN ABSENCE OF WATER : RESULTS}

\subsection{FTIR spectroscopy}

The kaolinite sample is now wetted using anhydrous toluene solution, with the same asphaltenes. 
Transmission IR spectra of the O-H stretching region of kaolinite before and after contact with asphaltenes in anhydrous toluene solution are shown in figure 3 .

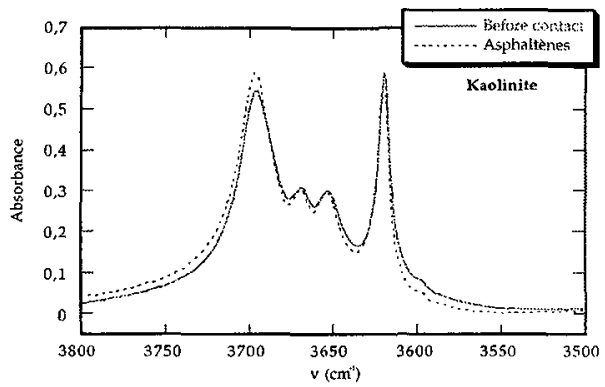

Figure 3 : FTIR transmission spectra of kaolinite before and after contact with asphaltenes in anhydrous toluene solution.

We can see in figure 3 that the relative intensities of the bands located at $3697 \mathrm{~cm}^{-1}$ are opposite to those observed in presence and absence of water. We have now an increase of the band intensity without shift. This result suggests that the water influences the asphaltenes adsorption process.

\subsection{X-ray absorption spectroscopy}

In absence of water, the spectra recorded at the $\mathrm{Al}$ K-edge and at the $\mathrm{Si} \mathrm{K}$-edge before and after contact with asphaltenes are superimposable (not shown here) : no modification of the local arrangement around Al atoms was observed; which is consistent with the FTIR results : the asphaltenes adsorption process appears to be different with and without water in the toluene solution.

\section{DISCUSSION AND CONCLUSION}

FTIR and XAS spectroscopies have been used to characterize the absorption phenomenon of asphaltenes on kaolinite and illite, at the microscopic level.

Infrared results show that only the $\mathrm{OH}$ surface of the kaolinite is sensitive to the contact with asphaltenes. The XANES and EXAFS results at the Al K-edge confirm the role of these surface groups, the local order of Al (the surface OH are linked to $\mathrm{Al}$ atoms) in the kaolinite being the proof of the adsorption process. However, the Si environment of the kaolinite remains insensitive to the contact, Si are not linked to $\mathrm{OH}$ groups.

For the illite phase, $\mathrm{Si}$ and $\mathrm{Al}$ environments are in each case not sensitive to the adsorption. Consequently, it is possible to explain the contrasts of wettability observed in the clays by structural differences between kaolinite and illite. More precisely, we pointed out the role of the Al-OH linkages located at the surface of the clays in the adsorption process. The presence of these groups at the grain surface can be associated with the affinity of asphaltenes to the surface with respect to water.

The asphaltenes adsorption process for kaolinite involved in absence of water is clearly different than in the presence of water: the surface $\mathrm{OH}$ are always sensitive to the phenomenon, but the vibrations are different. XAFS results don't show any modifications around $\mathrm{Al}$ atoms.

These results suggest that the presence of water in the asphaltenes adsorption process induces different modifications of the local arrangement of the Al-OH grain surfaces. It is now very important to progress in the understanding, to the atomic scale, of the interactions between oils and kaolinite by simplifying the adsorption process involved. To accomplish this, it is necessary to wet clays with model organic molecules which display simpler structures than asphaltenes. This work is currently in progress.

\section{Acknowledgements}

This work was partially supported through the CNRS-ARTEP research program (Etudes sur l'origine des contrastes de mouillabilité observés entre minéraux argileux des roches reservoir ; numéro de contrat : $92 \mathrm{~N} 80 / 0026$ ). The authors thank A. Saada, B. Siffert, T. Zoungrana and J.M. Douillard for providing the clay samples. C. Durand, N. Zanier and B. Moisson are thanked for their precious heip concerning the IR protocol experiments.

\section{References}

[1] Cuiec L.; Interfacial phenomena in oil recovery 36 (Morrow N.R Ed,, Marcel Dekker Inc, New York 1991) pp. 319-376.

[2] Saada A., Siffert B., Papirer E., J Colloids and Interfaces Sci. 174 (1995) 185-190.

[3] Siffert B., Jada A.. Wersinger E., Colloids and Surfaces 69 (1992) 41-45.

[4] Ledoux R., White JL., Science 143 (1964) 244-246.

[5] Bantignies J.-L.. Cartier dit Moulin C., Dexpert H., Flank AM., Williams G., C R Acad Sci Paris Ha 320 (1995) 699-709.

[6] Bantignies J.-L., Cartier dit Moulin C., Dexpert H., Clays \& Clay Miner. (1996) to be published. 